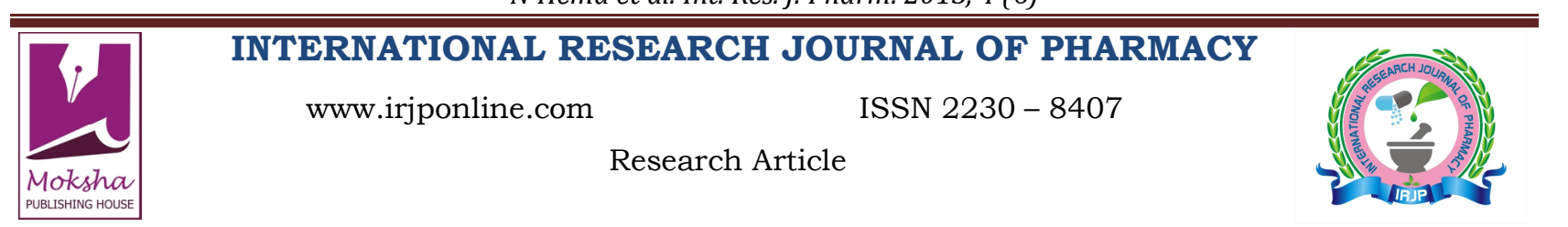

\title{
EVALUATION OF PHYSICOCHEMICAL STANDARDS OF CYPERUS ROTUNDUS RHIZOME WITH PHYTOCHEMICAL AND HPTLC PROFILING OF ITS EXTRACTS
}

\author{
$\mathrm{N} \mathrm{Hema}^{1}$, A Ramakrishna ${ }^{2}$, KN Sunil Kumar ${ }^{3}$, N Anupama ${ }^{4} *$
}

${ }^{1}$ Lecturer, Department of Anatomy, Yenepoya Medical College, Yenepoya University, India

${ }^{2}$ Professor and Head, Department of Anatomy, Yenepoya Medical College, Yenepoya University, India

${ }^{3}$ Senior Research Officer- Pharmacognosy, SDM Centre for Research in Ayurveda and Allied Sciences, Kuthpady, Udupi, India

${ }^{4}$ Associate Professor, Department of Physiology, Kasturba Medical College, Mangalore, Manipal University, India

*Corresponding Author Email: anupamavsharma@yahoo.com

Article Received on: 13/03/13 Revised on: 08/04/13 Approved for publication: 12/05/13

DOI: $10.7897 / 2230-8407.04630$

IRJP is an official publication of Moksha Publishing House. Website: www.mokshaph.com

(C) All rights reserved.

\section{ABSTRACT}

Cyperus rotundus (Musta), is a medicinal plant growing in tropical, sub-tropical and temperate regions having many pharmacological and medicinal characteristics. The current study attempts to standardize the extracts of raw drug Musta as per pharmacopoeial requirement. Roots and rhizomes of Musta sold in the markets of Mangalore were collected. Test sample was analysed for ash and extractive values. Tests for phytochemicals like alkaloids, flavonoids, steroids, phenols, carbohydrates, saponins, tannins and coumarins were performed in both ethanolic and aqueous extracts. Total phenolic content of the extracts were done as per standard protocol. Fingerprint profile of ethanolic and aqueous extract has been derived by photodocumentation and HPTLC densitometric scan. Ash values, extractive values, phytochemical tests, total phenol content and the HPTLC fingerprint of the Musta has been derived from the current study. The set of values obtained from the studies can be used as standards for testing, standardization and quality control of medicinal materials sold as Musta.

Keywords: Physico- chemical, phytochemical, total phenol, HPTLC profiling

\section{INTRODUCTION}

In this era where modern medicines are front runners in treating diseases of all kinds, Indian system of medicine has been able to gain a foothold and is becoming popular. The Ayurvedic system of medicine remedies are basically formulated using various medicinal plants. For many centuries, plants have provided a rich source of therapeutic agents and bases for synthetic drugs. Despite the great development of organic synthesis, currently $25 \%$ of prescribed drugs worldwide are still derived from plant sources, showing that plant species are still an important source of new drugs for diseases that continue to lack a cure, such as cancer ${ }^{1}$. Although herbs have proved to be highly curative, their standardization is a must before formulating medicines using them, which will help to ensure the quality, safety and efficacy of these herbal medicines. Even if the morphologic and microscopic characters are helpful to establish the identity of any herb, finding their physical and chemical constituents will provide thorough knowledge for authentication of the chemical characteristics. For the identification of herbs and their constituents, WHO guidelines recommend the fingerprinting methods to meet the universal standards of quality control of the herbal formulations $^{2}$. Along with other physico-chemical characterization, High performance thin layer chromatography (HPTLC) is more innovative, consistent and efficient method used for identification and separation of constituents in the herb or any herbal formulations ${ }^{3}$. Cyperus rotundus, a member of Cyperaceae and vernacularly called as Nagarmotha is medicinal herb and has gained its own recognition in principles of Ayurveda. It grows in tropical, sub-tropical and temperate regions. Based on different parts it has vivid uses. Many pharmacological and medicinal characteristics like anti-diabetic ${ }^{4}$ anti-diarrhoeal ${ }^{5}$, cytoprotective $^{6}$, anti-mutagenic ${ }^{7}$, antioxidant ${ }^{8}$, anti-malarial ${ }^{9}$, anti-inflammatory, anti-pyretic and analgesic ${ }^{10}$ are exhibited by this plant and has proved to be a multi-purpose medicinal herb. Rhizomes of Cyperus rotundus is one of the oldest medicinal plants used to treat dysmenorrheal and menstrual irregularities ${ }^{11}$. Presence of polyphenol, flavonol glycoside, alkaloid, saponins, sesquiterpenoids and essential oil were revealed from phytochemical investigations of Cyperus rotundus rhizome ${ }^{12,13}$. The present study is an attempt to investigate the physico-chemical, preliminary phytochemical, total phenol and HPTLC fingerprint profiling of aqueous and ethanol extracts of rhizomes of Cyperus rotundus.

\section{MATERIALS AND METHODS}

\section{Collection and Identification of the herb}

Rhizomes of Cyperus rotundus were collected from local Ayurvedic pharmacy in Mangalore. The plant material was examined at Pharmacognosy department of SDM Center for Research in Ayurveda and Allied Sciences, Udupi and sample specimen (No.11110101) was maintained for further references. The dried rhizomes were coarsely powdered and preserved in air tight container for further studies.

\section{Preparation of the extracts}

Ethanolic and aqueous extracts were prepared as per the standard procedures explained by Raaman ${ }^{14}$.

\section{Physico-chemical characters}

The various physico-chemical parameters like loss on drying at $105^{\circ} \mathrm{C}$, total ash, acid insoluble ash, water soluble ash, ethanol soluble extractive and water soluble extractive were determined according to the standard procedure prescribed in Ayurvedic Pharmacopeia of India ${ }^{15}$. 
Table 1: Physicochemical parameters of C. Rotundus

\begin{tabular}{|c|c|}
\hline Parameter & Result $\mathbf{n}=\mathbf{3}(\% \mathrm{w} / \mathrm{w})$ \\
\hline Loss on drying at $105^{\circ} \mathrm{C}$ & 12.65 \\
Total ash & 3.72 \\
Acid insoluble ash & 2.50 \\
Water soluble ash & 1.54 \\
Water soluble extractive & 5.2 \\
Ethanol soluble extractive & 1.9 \\
\hline
\end{tabular}

Table 3: Total phenolic content

\begin{tabular}{|c|c|}
\hline Parameter & Results $(\% \mathrm{w} / \mathrm{w})$ \\
\hline Crude drug & 8.625 \\
\hline Ethanol extract & 61.121 \\
\hline Aqueous extract & 74.853 \\
\hline
\end{tabular}

Table 4: $\mathbf{R}_{\mathrm{f}}$ Values of Ethanolic Extract of $\boldsymbol{C}$. Rotundus

\begin{tabular}{|c|c|c|}
\hline At UV 254 nm & At UV 366 nm & Post-derivatisation \\
\hline- & 0.03 F L Blue & - \\
\hline 0.12 Green & - & - \\
\hline- & - & 0.15 Violet \\
\hline 0.21 Green & - & 0.21 Pink \\
\hline- & 0.27 F L Blue & - \\
\hline 0.28 Green & - & 0.28 Violet \\
\hline- & 0.34 F L Blue & - \\
\hline 0.36 Green & - & 0.36 Violet \\
\hline 0.43 Green & - & 0.43 Yellow \\
\hline 0.47 Green & - & - \\
\hline 0.51 Green & - & 0.51 Violet \\
\hline 0.57 D Green & - & 0.57 Violet \\
\hline 0.62 D Green & 0.62 F M Blue & - \\
\hline 0.68 Green & - & 0.68 Pink \\
\hline 0.75 Green & - & 0.75 Purple \\
\hline 0.81 Green & - & - \\
\hline- & 0.85 F D Blue & - \\
\hline - & - & 0.87 Purple \\
\hline - & - & 0.96 Purple \\
\hline \multicolumn{2}{|r|}{ L - Light; M - Medium; D - Dark } \\
\hline
\end{tabular}

\section{Preliminary phytochemical analysis}

This analysis is to detect the presence of various organic functional groups, which is the indicative of type of phytochemicals present in the plant. These tests indicate the presence different class of constituents present in the extract. The tests for alkaloids, carbohydrates, steroids, saponins, tanins, flavonoids, phenols, coumarins, triterpinoids and carboxylic acid were performed as per the methodology mentioned by Harborne ${ }^{16}$.

\section{Estimation of total phenolic content}

Total phenolic content of the crude drug, aqueous extract and ethanolic extract were done according to standard procedure explained by Ayurvedic pharmacopoeia of India ${ }^{17} .1 \mathrm{ml}$ of Folin's reagent diluted with $1 \mathrm{ml}$ of water $20 \mathrm{~g}$ of $\mathrm{Na}_{2} \mathrm{CO}_{3}$ dissolved in $100 \mathrm{ml}$ of water at $70-80^{\circ} \mathrm{C}$ and cooled it overnight. After adding the reagents, the mixture was incubated at room temperature for $40 \mathrm{~min}$ in dark and absorbance of the sample was measured at $725 \mathrm{~nm}$ in a UV spectrophotometer. Tannic acid was used as standard (1 $\mathrm{mg} / \mathrm{ml})$. All the tests were performed in triplicates . The phenol content was estimated from the calibration curve of standard tannic acid obtained by plotting concentration $v s$. absorbance.

\section{HPTLC}

$1 \mathrm{~g}$ of the plant powder was extracted with $10 \mathrm{ml}$ of solvent 2 times by cold percolation for 48 hrs. $25 \mu \mathrm{l}$ of the ethanol extract was applied on a pre-coated silica gel F254 on aluminum plates to a band width of $8 \mathrm{~mm}$ using Linomat 5
Table 2: Results of Preliminary Phytochemical Tests

\begin{tabular}{|c|c|c|}
\hline Test & Ethanolic extract & Aqueous extract \\
\hline Alkaloid & - & - \\
\hline Coumarin & + & + \\
\hline Flavanoid & - & - \\
\hline Carbohydrate & + & + \\
\hline Steroid & + & + \\
\hline Phenol & + & + \\
\hline Tannin & + & - \\
\hline Terpenoid & + & - \\
\hline Resins & - & - \\
\hline Saponins & + & + \\
\hline
\end{tabular}

Table 5: $\mathbf{R}_{\mathrm{f}}$ values of aqueous extract of $C$. rotundus

\begin{tabular}{|c|c|c|}
\hline At UV 254 nm & At UV 366 nm & Post - derivatisation \\
\hline 0.03 L Green & 0.03 Blue & - \\
\hline- & - & 0.06 L Pink \\
\hline- & 0.14 Blue & 0.14 L Pink \\
\hline- & 0.18 Blue & - \\
\hline- & 0.22 Blue & - \\
\hline 0.28 L Green & - & 0.28 Brown \\
\hline- & 0.32 Blue & - \\
\hline- & - & 0.39 Blue \\
\hline- & 0.42 Blue & - \\
\hline- & 0.48 Blue & - \\
\hline- & - & 0.50 L Blue \\
\hline 0.56 L Green & - & - \\
\hline- & 0.59 Blue & 0.59 L Blue \\
\hline- & - & 0.66 L Violet \\
\hline- & 0.73 Blue & 0.73 L Blue \\
\hline 0.82 L Green & 0.82 Blue & 0.82 L Blue \\
\hline 0.87 L Green & 0.87 Blue & 0.87 L Blue \\
\hline- & 0.95 Blue & 0.95 L Blue \\
\hline
\end{tabular}

L - Light

TLC applicator. The applied plate was developed in suitable solvent system and the developed plates were visualized and scanned under UV 254, 366 and after derivatisation in vanillin-sulphuric acid spray reagent. $\mathrm{R}_{\mathrm{f}}$, colour of the spots and densitometric scan were recorded. Toluene - ethyl acetate (8:2) and ethyl acetate: formic acid: water (8.8:0.6:0.6) were used as solvent system for development of ethanolic and aqueous extracts respectively ${ }^{18}$.

\section{RESULTS AND DISCUSSION}

The physico-chemical results are depicted in Table 1. The results of phyto-chemical investigation of aqueous and ethanolic extracts were given in Table 2. The extract was tested positive for coumarins, carbohydrates, steroids, phenols and saponins. But in ethanolic extract, in addition to above constituents, terpenoids and tannins are also seen. Alkaloids, flavonoids and resins are absent in both the extracts. The results of total phenolic content of crude drug, aqueous extract and ethanolic extract is given in Table 3 . Water soluble extract is found to contain more of phenol content than ethanolic extract. Figure 1 shows the TLC photo documentation of ethanolic extracts of Cyperus rotundus at UV $254 \mathrm{~nm}$ and UV $366 \mathrm{~nm}$ using toluene: ethyl acetate solvent at 8:2 ratio and Table 4 gives the $\mathrm{Rf}$ values of the same.12 spots were seen at UV $254 \mathrm{~nm}, 5$ spots at UV 366 $\mathrm{nm}$ and 11 spots at post-derivatisation. In HPTLC densitometric scan of same extract at UV $254 \mathrm{~nm}, 15$ peaks were obtained (Figure 2). Here at $12^{\text {th }}$ peak with $\mathrm{Rf}$ value 0.67 has maximum area percentage i.e.34.11\%. At UV 366 $\mathrm{nm}$ only 3 peaks were observed with maximum height at $2^{\text {nd }}$ 
peak having $0.60 \mathrm{Rf}$ value and $85.36 \%$ of area percentage (Figure 3). Figure 4 shows the TLC photo documentation of aqueous extract of C.rotundus at UV $254 \mathrm{~nm}$ and UV $366 \mathrm{~nm}$ using solvent system - Ethyl acetate: Formic acid: Water (8.8:0.6:0.6). Table 5 gives the $\mathrm{Rf}$ values for the same. 5 spots were seen at UV $254 \mathrm{~nm}, 12$ spots at UV $366 \mathrm{~nm}$ and 11 spots at post-derivatisation. In HPTLC densitometric scan of this extract at UV $254 \mathrm{~nm}, 9$ peaks were obtained (Figure 5). Here at $9^{\text {th }}$ peak with $\mathrm{R}_{\mathrm{f}}$ value 0.93 has maximum area percentage i.e.44.94\%. At UV $366 \mathrm{~nm}$ only 11 peaks were observed with maximum height at 1 st peak having $0.02 \mathrm{Rf}$ value and $43.38 \%$ of area percentage (Figure 6 ).

\section{CONCLUSION}

The physio-chemical, phytochemical, total phenolic content and HPTLC fingerprint reported in the current study could be used as the analytical tool for the standardization of the rhizome of Cyperus rotundus since these features are distinctive for the identification of Musta. It could help in laying down standards as per WHO guidelines for authentication of the drug and also may aid to distinguish the above drug from its substitute or adulterants if any.

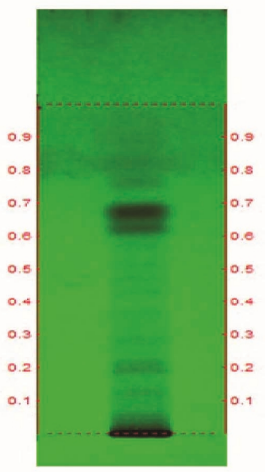

At UV $254 \mathrm{~nm}$

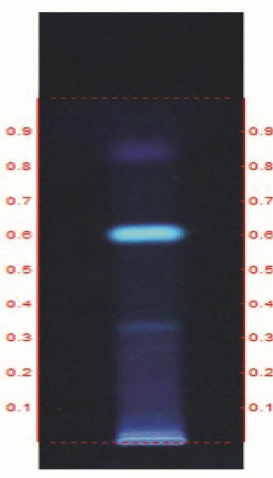

At UV $366 \mathrm{~nm}$

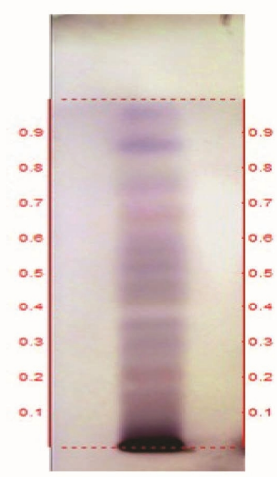

Post derivatisation

Solvent system - Toluene : Ethyl acetate (8:2)

Figure 1. TLC photodocumentation of alcoholic extract of $C$. rotundus $(25 \mu \mathrm{I})$

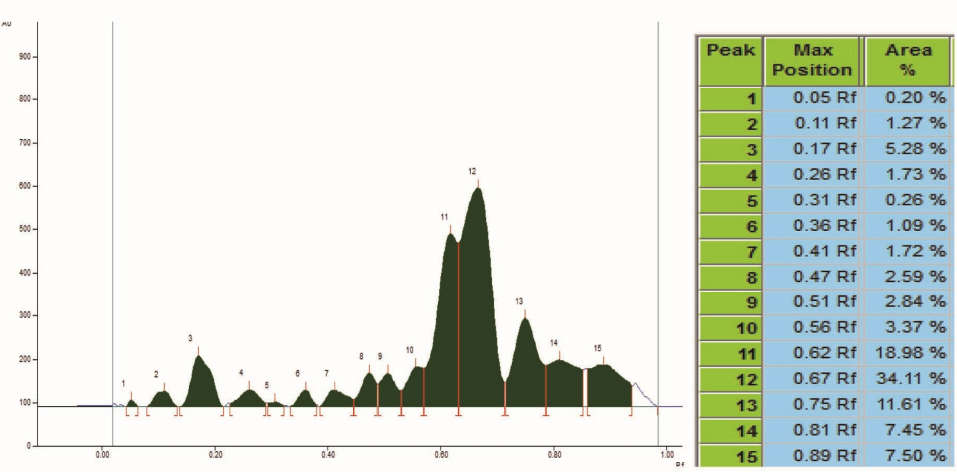

Figure 2. HPTLC Densitometric scan of ethanolic extract of $C$. rotundus at UV $254 \mathrm{~nm}$

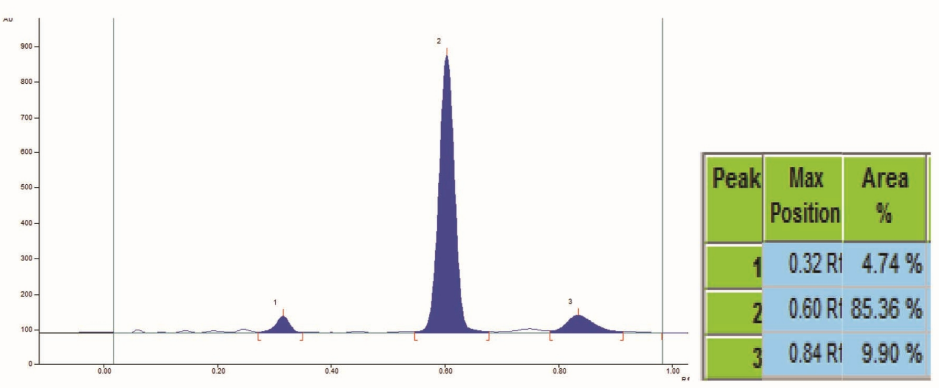

Figure 3. HPTLC Densitometric scan of ethanolic extract of $C$. rotundus at UV $366 \mathrm{~nm}$ 


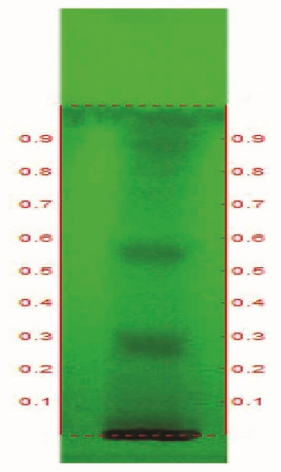

At UV $254 \mathrm{~nm}$

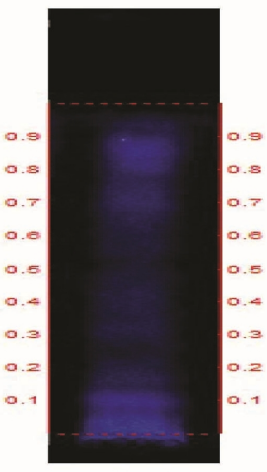

At UV $366 \mathrm{~nm}$

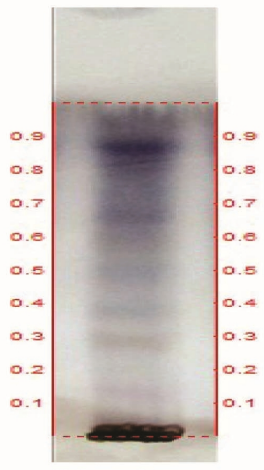

Post derivatisation

Solvent system - Ethyl acetate: Formic acid: Water (8.8:0.6:0.6)

Figure 4. TLC photodocumentation of aqueous extract of $C$. rotundus

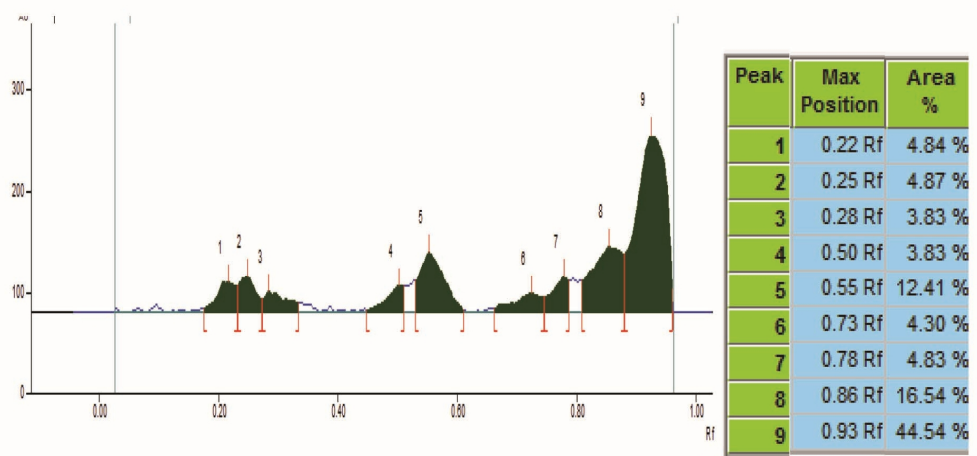

Figure 5. HPTLC Densitometric scan of aqueous extract of $C$. rotundus at UV $254 \mathrm{~nm}$

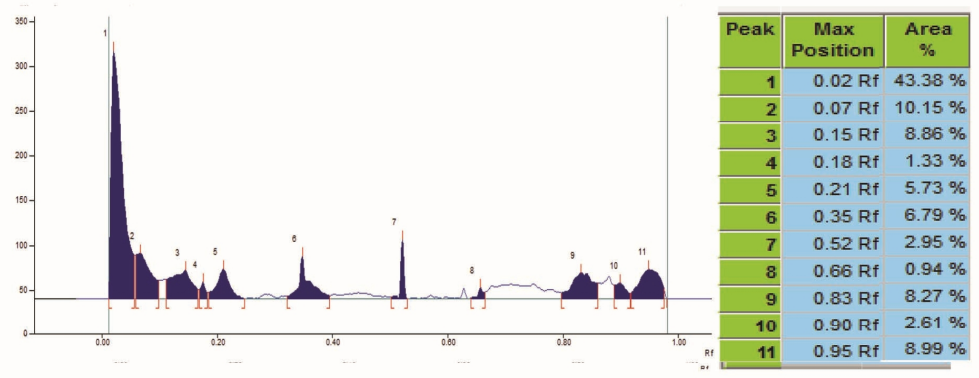

Figure 6. HPTLC Densitometric scan of aqueous extract of $C$. rotundus at UV $366 \mathrm{~nm}$

\section{ACKNOWLEDGEMENT}

The authors are thankful to Yenepoya University for giving permission to conduct the above study. Authors gratefully acknowledge Dr. B. Ravishankar, Director, SDM Centre for Research in Ayurveda and Allied Sciences, Udupi for his kind suggestion, B Sangeetha and M Rajalekshmi for their help in analysis.

\section{REFERENCES}

1. Rates SM. Plants as source of drugs. Toxicon 2001; 39: 603-613. http://dx.doi.org/10.1016/S0041-0101(00)00154-9

2. WHO: Guidelines for methodology on research and evaluation of traditional medicine; 2000.

3. Liang YZ, Xie P, Chan K. Quality control of herbal medicines. J. Chromatogr. B 2004; 812: 53-70. http://dx.doi.org/10.1016/j.jchromb.2 004.08 .041
4. Raut NA, Gaikwad NJ. Antidiabetic activity of hydroethanolic extract of Cyperus rotundus in alloxan induced diabetes in rats. Fitoterapia 2006; 77: $\quad 585-588 . \quad$ http://dx.doi.org/10.1016/j.fitote.2006.09.006 PMid: 17056202

5. Uddin SJ, Mondal K, Shilpi JA, Rahman MT. Antidiarrhoeal activity of Cyperus rotundus. Fitoterapia 2006; 77: 134-136. http://dx.doi.org /10.1016/j.fitote.2004.11.011 PMid:16376024

6. Zhu M, Luk HH, Fung HS, Luk CT. Cytoprotectiveeffecst of Cyperus rotundus against ethanol induced gastric ulcerations in rats. Phytother Res 1997; 11: $392 \quad$-394. http://dx.doi.org/10.1002/(SICI)10991573(199708)11:5<392::AID-PTR113>3.0.CO;2-1

7. Kilani S, Ben Ammar R, Bouhlel I, Abdelwahed A, Hayder N, Mahmoud A, Ghedira K, Chekir-Ghedira L. Investigation of extracts from(Tunisian) Cyperus rotundus as antimutagens and radical scavengers. Environ Toxicol Phar 2005; 20: 478-484. http:/ /dx.doi.org/10.1016/j.etap.2005.05.012 PMid:21783629 
8. Pal DK, Dutta S. Evaluation of antioxidant activity of the roots of Cyperus rotundus L. Indian J Pharm Sci 2006; 68: 256-258. http:/ dx.doi.org/10.4103/0250-474X.25731

9. Weenan H, Nkunya MH, Bray DH, Mwasumbi Lb, Kinabo LS, Kilimali VA. Antimalarial activity of Tanzanian medicinal plants. Plants Medica 1990a; 56: 368-370. http://dx.doi.org/10.1055/s-2006-960984 PMid:2236289

10. Gupta MB, Palik TK, Singh N, Bhargava KP. Pharmacological studies to isolate the active constituents from Cyperus rotundus possessing antiinflammatory, antipyretic and analgesic activities. Indian J Med Res 1971; 59: 76-82. PMid:5574385

11. Bhattarai NK. Folk herbal remedies for diarrhea and dysentery in central Nepal. Fitoterapia 1993; 64: 243-250.

12. Nagulendran KR, Velavan S, Mahesh R, Hazeena begum V. In vitro antioxidant activity and total polyphenolic content of Cyperus rotundus rhizomes. E-Journal of chemistry 2007; 4(3): 440-449.

13. Venkatsubramanian P, Kumar S, Nair SNV. Morphological, microscopical and physico-chemical investigations on the rhizomes of Cyperus rotundus Linn. J AyuInt Med 2010; 1(1): 33-39.
14. Raaman N. Phytochemical Techniques. New India Publishing Agency, New Delhi 2006; 9-18

15. Ayurvedic Pharmacopoeia of India Part I Vol. 3 p. 129-30

16. Harborne JB. (Phytochemical Methods. Jackman H. (Ed.), London; 1973. p. 70.

17. Ayurvedic Pharmacopoeia of India.NewDelhi: Ministry of Health and Family Welfare, Department of Ayurveda, Yoga \&Naturopathy, Unani Siddha and Homeopathy; 2008, 6. p. 336

18. Sethi PD. High Performance Thin Layer Chromatography (1st Edition). New Delhi: CBS Publishers and Distributors; 1996, X. p. 1-56

Cite this article as:

N Hema, A. Ramakrishna, KN Sunil Kumar, N Anupama. Evaluation of physicochemical standards of Cyperus rotundus rhizome with phytochemical and HPTLC profiling of its extracts. Int. Res. J. Pharm. 2013; 4(6):133-137

Source of support: Nil, Conflict of interest: None Declared 